\title{
Stillbirth risk with social class and deprivation: no evidence for increasing inequality
}

\author{
T.J.B. Dummer ${ }^{\mathrm{a}}$, H.O. Dickinson ${ }^{\mathrm{a}, *}$, M.S. Pearce ${ }^{\mathrm{a}}$, M.E. Charlton ${ }^{\mathrm{b}}$, L. Parker ${ }^{\mathrm{a}}$ \\ ${ }^{a}$ North of England Children's Cancer Research Unit, Department of Child Health, University of Newcastle upon Tyne, Royal Victoria Infirmary, \\ Queen Victoria Road, Newcastle upon Tyne, NE1 4LP, England, UK \\ ${ }^{\mathrm{b}}$ Department of Geography, University of Newcastle upon Tyne, Daysh Building, Newcastle upon Tyne, NE1 7RU, England, UK \\ Received 2 December 1998; received in revised form 2 August 1999; accepted 23 August 1999
}

\begin{abstract}
The objective of this study was to determine whether inequality in stillbirth risk between social strata has changed over time. Subjects were all 288,869 births in Cumbria, northwest England, 1950-1993 and all 8,039,269 births in England and Wales, 1981-1992. Social class of Cumbrian babies was ascertained from birth registrations. Community deprivation scores were calculated from census data for (i) enumeration districts in Cumbria and (ii) county districts in England and Wales. The relative index of inequality was used to measure inequality of stillbirth risk between social strata. Results indicate inequality in stillbirth risk in Cumbria has fallen significantly since 1966 $(\mathrm{P} \leqslant 0.02)$ and was not evident in more recent time periods. In England and Wales, there was significant inequality in stillbirth risk in all time periods and no evidence that this has changed over time. Inequality in stillbirth risk has not increased and in some areas has attenuated in recent years. (c) 2000 Elsevier Science Inc. All rights reserved.
\end{abstract}

Keywords: Stillbirth; Deprivation; Social class; Inequality; Cohort study; Epidemiology

\section{Introduction}

Mortality and morbidity from a wide range of conditions and in all age groups are known to be higher in deprived communities [1-6]. There is also a substantial gradient in health outcome with social class [7-10]. Stillbirth rates have been less widely studied in this context, although they have also been shown to be higher in lower social classes and in deprived communities [7,8,11-15].

There is great concern that despite an overall trend to better health, the improvements in health have been greatest in the most affluent groups with less or no improvement in the health of the most deprived, thus creating an overall widening in the differentials in health [1,4].

This study investigates how differences in stillbirth rates across social strata have changed over time, both in Cumbria, 1950-1993, and throughout England and Wales, 19811992, in order to determine whether there is evidence of changing inequality in stillbirth risk.

\footnotetext{
* Corresponding author. Tel.: 0191202 3035; fax: 01912023060.

E-mail address: heather.dickinson@ncl.ac.uk (H.O. Dickinson)
}

\section{Methods}

In England and Wales from 1927 until 1 October 1992, a stillbirth was defined as a child born after the 28th week of pregnancy, which did not at any time after being completely expelled from its mother, breathe or show any sign of life. After 1 October 1992, a stillbirth was similarly defined as a fetal death, but deaths occurring from 24 completed weeks of gestation onwards were included [16-18]. These definitions exclude termination of pregnancy by induced abortion.

\subsection{Data sources and capture}

Data were assembled from four sources, and five software packages were used in the processing, aggregation, and analysis of the data (see Fig. 1).

\subsubsection{Cumbria: individual level data 1950-93}

The cohort studied consisted of all 287,901 live and 4,362 stillbirths to mothers usually resident in the County of Cumbria, northwest England between 1 January 1950 and 31 December 1993. The Cumbrian births cohort has been described in detail elsewhere [19-21]. In summary, all live and stillbirth registrations were obtained from the Office for National Statistics and entered into a computer database. Because underregistration of stillbirths is an acknowledged problem [22], public archives and hospital records in Cum- 


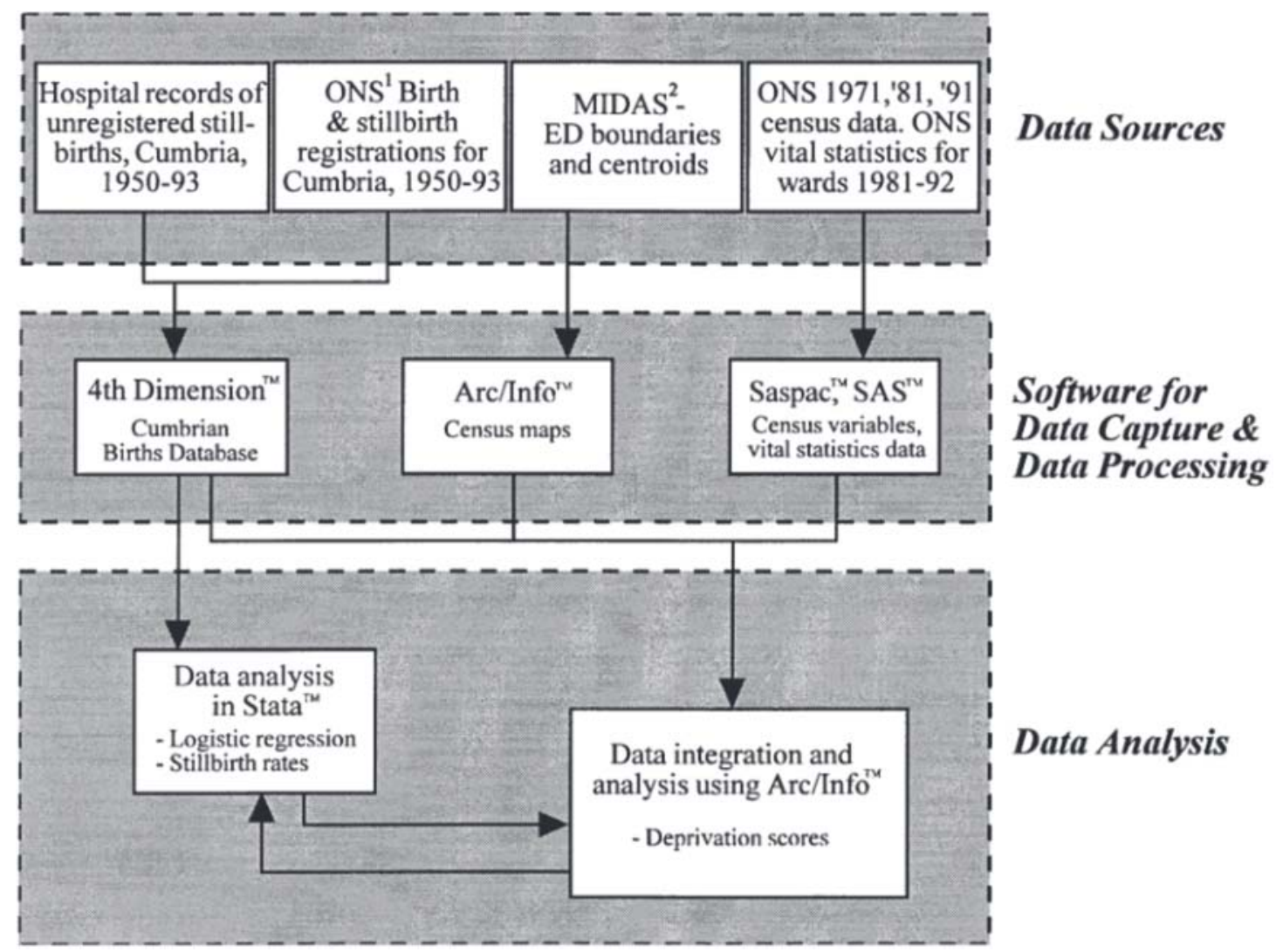

Fig. 1. Structure of the methodology. ${ }^{1}$ Office for National Statistics. ${ }^{2}$ Manchester Information Datasets and Associated Services.

bria and in regional referral centers outside Cumbria were searched for records of additional live and stillbirths to mothers resident in Cumbria; 27 (0.6\%) unregistered stillbirths were found.

The mother's residential address at the birth of the child was postcoded and hence each birth was grid referenced. The 3,352 live births and 42 stillbirths that could not be postcoded were excluded from the study. The father's occupation, as recorded on the birth certificate, was coded and hence the social class (I, II, III nonmanual, III manual, IV, $\mathrm{V}$, armed forces, and unknown) was derived [23]. If the father was not recorded on the birth certificate, the social class was coded as "father unrecorded.” Algorithms based on parents' names were used to identify siblings and multiple births and to assign birth order.

The following details of each birth within the cohort were used in the analysis: grid reference, social class, year of birth, birth order, multiple birth (yes/no), and live/stillbirth.

\subsubsection{Cumbria: community deprivation scores 1965-93}

Three measures of community deprivation at the enumeration district (ED) level were used: the Townsend [3], Department of the Environment (DoE) [24], and Jarman scores [25]. These scores were calculated from data extracted from the 1971, 1981, and 1991 censuses, the contributing variables being standardized within each census. For all the deprivation scores, a higher value indicates greater deprivation.

Digitized boundaries of 1991 EDs were obtained from Manchester Information Datasets and Associated Services (MIDAS), at Manchester Computing. No such data were available for the 1971 and 1981 censuses, so deprivation scores were interpolated between ED centroids. Hence, each birth was allocated a deprivation score for the ED and time period in which it fell.

\subsubsection{England and Wales: 1981-92}

Numbers of live and stillbirths by census wards for England and Wales for the period 1981-1992 were extracted from MIDAS. Because of differences in the identification of wards in the census and in the tabulations of vital statistics, the data were aggregated to the 403 county districts of England and Wales. Deprivation scores were then calculated from the 1981 and 1991 census data, standardizing the contributing variables within each census.

\subsection{Data analysis-Cumbrian data}

Within each time period stillbirth rates were calculated for all social classes; the population was also ranked by deprivation score, divided into quintiles of approximately equal populations and the stillbirth rate for each quintile was calculated. 
As the deprivation scores derived from different censuses were not strictly comparable, the data were stratified by time period (see Table 1). To investigate the change in the effect of deprivation over time, analysis was also undertaken for the time period 1966-1993 with the 1981 and 1991 deprivation score variables standardized to the 1971 census [26].

Inequality in stillbirth risk between social strata (social classes I-V or levels of deprivation score) in each time period was measured using the relative index of inequality (RII) $[27,28]$. This measures the trend in stillbirth risk across the social strata, allowing for the number of births in each group. Hence, comparisons of inequality in different time periods are not distorted by changes in the numbers of births in each group. An RII of 2 indicates a doubling of stillbirth risk between the top and the bottom of the social hierarchy. The RII was estimated using logistic regression [29], after adjusting for birth order, multiple births, and year of birth. The significance of the change in inequality over time was assessed from the interaction between RII and year of birth.

The odds ratio (OR) for the risk of stillbirth among children whose father was unrecorded compared to all others was also estimated using logistic regression, after adjusting for covariates as before.

Variables were retained in the logistic regression model if their significance $(\mathrm{P})$ as estimated by the likelihood ratio test statistic was less than 0.05 , both for inclusion in a forwards step and for elimination in subsequent backwards steps $[29,30]$. To allow for the possible effects of geographical clustering, robust estimates of variance were used for the final model [31].

The goodness of fit of the final logistic regression models was assessed using the Hosmer and Lemeshow deciles of risk statistic [29], which compares the observed and expected numbers of stillbirths in 10 groups containing approximately equal numbers of births.

\subsection{Data analysis-England and Wales}

As for Cumbria, stillbirth rates for each time period were calculated for each quintile of population ranked by deprivation score. The data were stratified by time period (Table 1) and stratified geographically into north/south (counties above and below a line running roughly from the Severn estuary to the Wash). The RII was used to assess inequality in stillbirth risk between county districts with different levels of deprivation score. As before, the change in inequality with time was assessed by standardizing the 1991 deprivation score variables to the 1981 census [26] and assessing the interaction between inequality and time period of birth.

\section{Results}

The observed stillbirth rate declined dramatically in England and Wales between 1950 and 1993 and a similar decline was observed in Cumbria. The proportion of births whose father was unrecorded increased from the mid 1960s (Fig. 2).

There was a decline in deprivation in Cumbria, as measured by the Townsend score, although the Jarman and DoE scores showed an increase in the highest levels of deprivation relative to the 1971 census data (Table 2).

The range of deprivation scores was narrower in Cumbria than in England and Wales in both the 1981 and 1991 censuses (Fig. 3).

\subsection{Cumbria - analysis by enumeration district}

Table 3 shows the unadjusted stillbirth rates for each social class and for the quintiles of population by deprivation score and time period. While the stillbirth rate in social class $\mathrm{V}$ was approximately double that in social class $\mathrm{I}$ in the early time periods (1950-1965 and 1966-1975), the rates in these social classes were much closer in later time periods. In contrast, the stillbirth rates among babies whose father was unrecorded were approximately twice those in social clas IIIm (the class with the most births and therefore the most valid comparison class) in all time periods. In order to assess the significance of potential changes and to investigate whether they were due to confounding factors, a logistic regression analysis was carried out, adjusting for factors that are known to affect the stillbirth rate.

Table 4 shows the results of this adjusted logistic regression analysis. For births in the less advantaged social classes, the risk of stillbirth was significantly higher in the earlier time periods (1950-1975), but not subsequently. The increase in the RII from 1.52 (95\% CI: 1.32-1.76) in 1950-

Table 1

The measures of deprivation used and the time periods and areas to which they were applied

\begin{tabular}{|c|c|c|c|c|c|c|c|}
\hline \multirow[b]{2}{*}{ Time period } & \multirow[b]{2}{*}{ Census data used } & \multirow[b]{2}{*}{ Area } & \multirow[b]{2}{*}{ Areal unit of analysis } & \multirow[b]{2}{*}{ Social class } & \multicolumn{3}{|c|}{ Measure of community deprivation } \\
\hline & & & & & Townsend score & DoE score & Jarman score \\
\hline $1950-65$ & - & Cumbria & Enumeration District & $\checkmark$ & - & - & - \\
\hline $1966-75$ & 1971 & Cumbria & Enumeration District & $\checkmark$ & $\checkmark$ & $\checkmark$ & $\checkmark$ \\
\hline $1976-85$ & 1981 & Cumbria & Enumeration District & $\checkmark$ & $\checkmark$ & $\checkmark$ & $\checkmark$ \\
\hline 1986-93 & 1991 & Cumbria & Enumeration District & $\checkmark$ & $\checkmark$ & $\checkmark$ & $\checkmark$ \\
\hline 1966-93 & 1971, 1981, 1991 & Cumbria & Enumeration District & $\checkmark$ & $\checkmark$ & $\checkmark$ & $\checkmark$ \\
\hline $1981-85$ & 1981 & England \& Wales & County District & - & $\checkmark$ & $\checkmark$ & $\checkmark$ \\
\hline 1986-92 & 1991 & England \& Wales & County District & - & $\checkmark$ & $\checkmark$ & $\checkmark$ \\
\hline 1981-92 & 1981, 1991 & England \& Wales & County District & - & $\checkmark$ & $\checkmark$ & $\checkmark$ \\
\hline
\end{tabular}




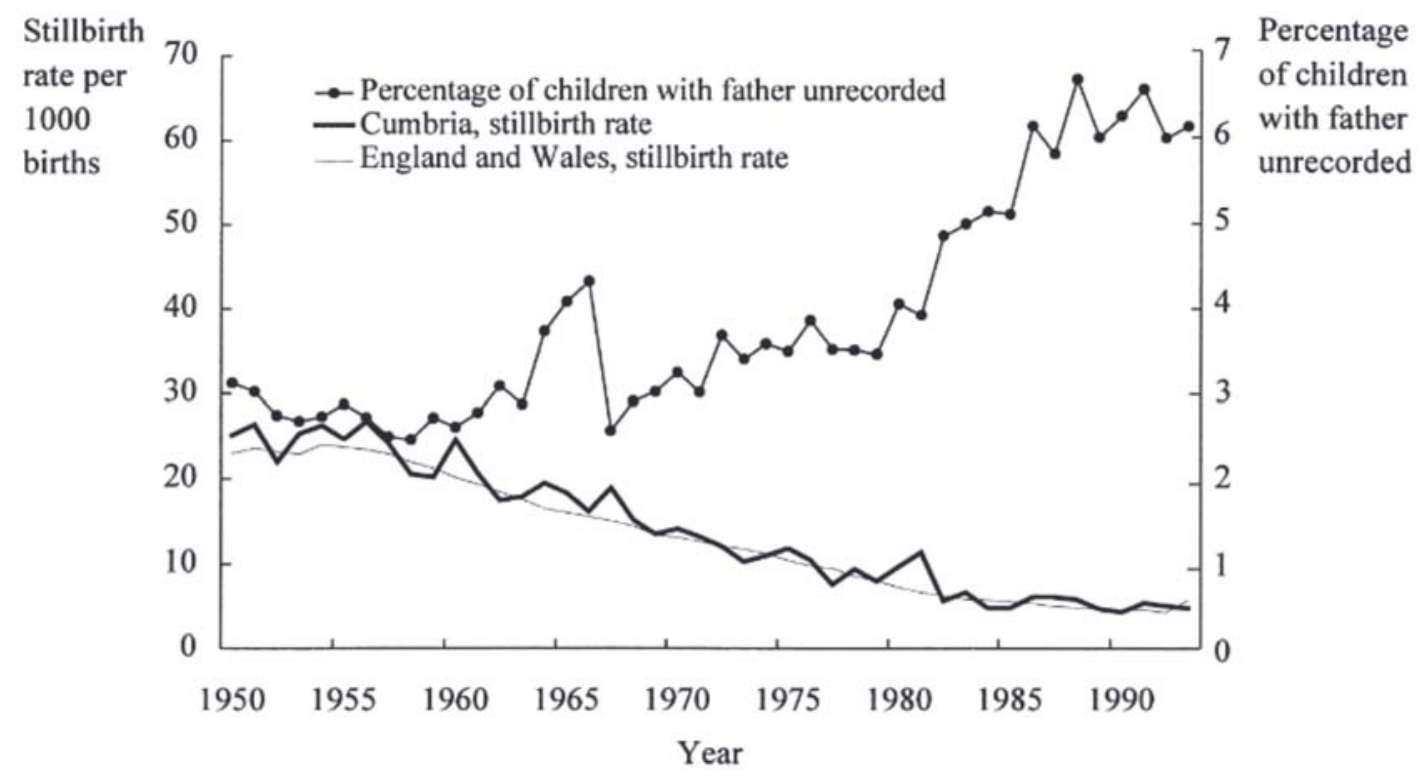

Fig. 2. Comparison of stillbirth rates in Cumbria with England and Wales and percentage of children with father unrecorded, for Cumbria, $1950-93$.

1965 to 2.00 (95\% CI: $1.55-2.58)$ in 1966-1975 was due to a greater proportional fall in stillbirth rates among the more advantaged social classes in this time period (see Table 3). This situation was later reversed, resulting in an RII of 1.17 (95\% CI: 0.81-1.68) in 1976-1985 and a similar RII in 1986-1993. A test of the interaction between RII and year of birth confirmed that this narrowing of inequality of stillbirth risk between social classes I-V from 1966 onwards was statistically significant $(P=0.01)$. However, the higher risk for babies whose fathers were unrecorded was evident over the entire 44 years of the study, and a similar test of interaction confirmed that the attenuation in inequality from an odds ratio of 2.57 (95\% CI: 2.03-3.26) in 1966-1975 to 1.90 (95\% CI: 1.28-2.81) in 1986-1993 was not significant $(\mathrm{P}=0.09)$.

There was significant inequality in stillbirth risk between mothers living in areas with different levels of deprivation in 1966-1975, but not in later time periods (Table 4). Use of

\section{Table 2}

Deprivation as measured in the 1981 and 1991 censuses relative to the 1971 census, in EDs in Cumbria [26]

\begin{tabular}{lcclc}
\hline Deprivation score & Mean & Minimum & Maximum & 95\% Percentile \\
\hline Townsend & & & & \\
1971 census & 0 & -7.4 & 7.9 & 5.2 \\
1981 census & -0.1 & -7.4 & 7.9 & 5.6 \\
1991 census & -2.6 & -7.4 & 3.9 & 0.7 \\
DoE & & & & \\
1971 census & 0 & -13.4 & 12.8 & 7.2 \\
1981 census & 3.5 & -13.4 & 16.9 & 10.5 \\
1991 census & -0.1 & -13.4 & 17.8 & 10.0 \\
Jarman & & & & \\
1971 census & 0 & -58.4 & 33.7 & 19.0 \\
1981 census & 3.1 & -58.4 & 39.1 & 23.0 \\
1991 census & 15.0 & -58.4 & 87.1 & 46.5 \\
\hline
\end{tabular}

deprivation scores standardized to the 1971 census and a test of interaction between RII and year of birth allowed us to test whether the decline in RII over time was statistically significant. Very similar results were obtained for the RII in each time period, and inequality was shown to have attenuated significantly since $1966(\mathrm{P}=0.005,0.020$, and 0.002 for Townsend, DoE, and Jarman scores respectively).

During 1966-1975 individual social class and community deprivation (Townsend score) accounted independently for significant variation in the risk of stillbirth, after allowing for the effects of each other (RII social classes I-V $=1.85$ (95\% CI: 1.42-2.42), P < 0.001, after adjusting for deprivation; RII for Townsend score = 1.33 (95\% CI: 1.05-1.69), $\mathrm{P}=0.02$, after adjusting for social class). However, there was some confounding: for the period 1966-1993 two thirds of the births in the less advantaged social classes (IV, $\mathrm{V}$, armed forces, and unknown, father unrecorded) were to mothers living in EDs with deprivation scores below the median.

The goodness of fit of each of the best models in each time period was confirmed by the Hosmer and Lemeshow deciles of risk statistic $(\mathrm{P}>0.1)$.

\subsection{England and Wales-analysis by county district}

Table 5 shows stillbirth rates for England and Wales by quintiles of population and deprivation score for the two time periods: 1981-1985 and 1986-1992. The stillbirth rate for the highest level of deprivation remained 1.2-1.3 times that for the lowest level of deprivation in both time periods, indicating little apparent change in inequality. We proceeded, as before, to assess this formally, allowing for the north/south zones.

There was a significantly increased rate of stillbirth in the north compared to the south (OR $=1.13$, (95\% CI: 1.09- 


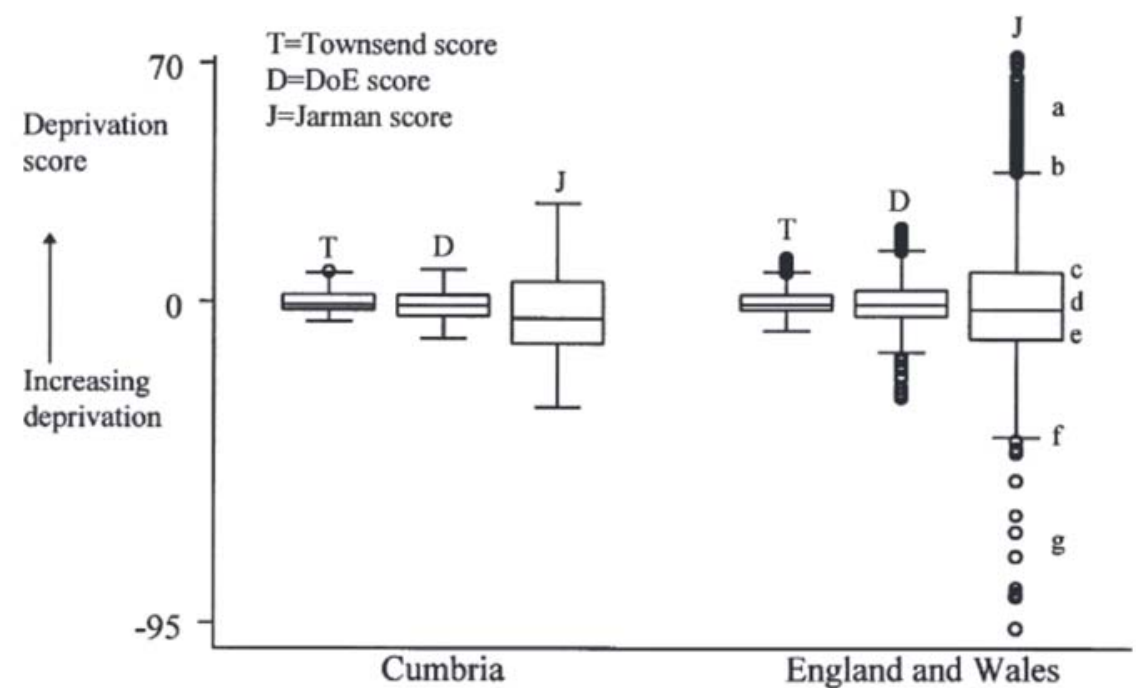

(i) 1981 Census

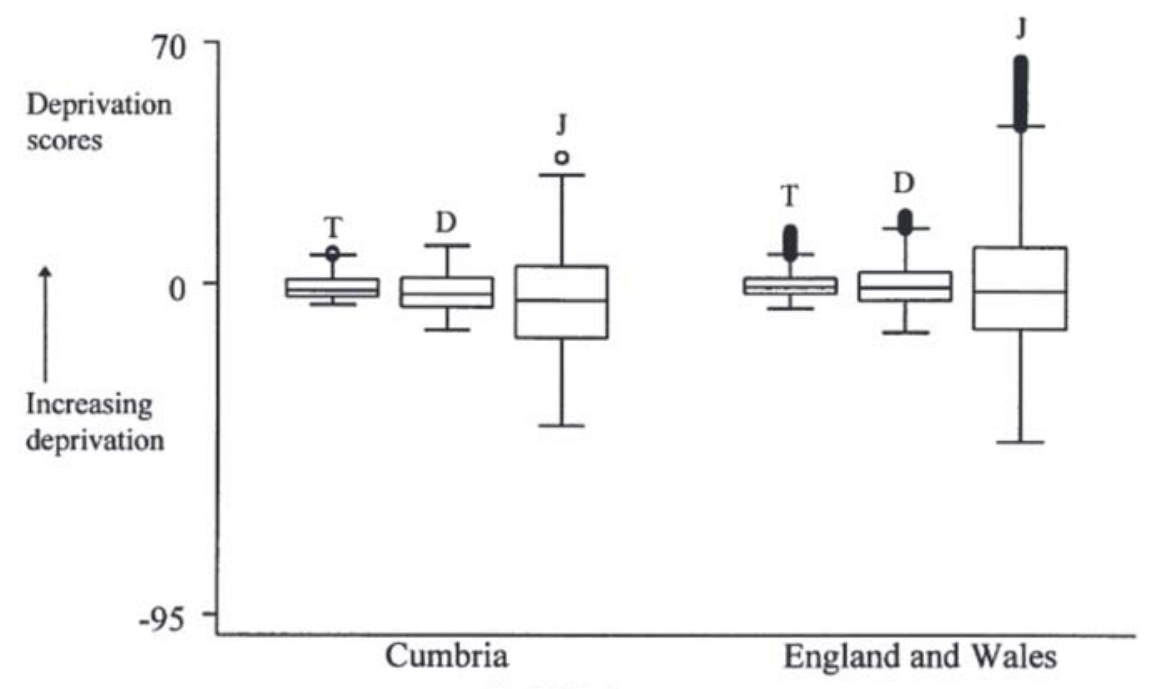

(ii) 1991 Census

Fig. 3. Box plots showing range of deprivation scores in wards in Cumbria and in England and Wales for (i) 1981 and (ii) 1991 censuses. a and g are outliers, $\mathrm{b}$ is defined as largest data point $\leqslant 75$ th percentile point +1.5 times interquartile range, $\mathrm{c}=75$ th percentile point, $\mathrm{d}=$ median, $\mathrm{e}=25$ th percentile point, $\mathrm{f}$ is defined as smallest data point $\geqslant 25$ th percentile point -1.5 times interquartile range.

1.17), $\mathrm{P}<0.001)$, which decreased but remained highly significant $(\mathrm{OR}=1.08$, (95\% CI: 1.05-1.11), $\mathrm{P}<0.001)$ after allowing for deprivation (Townsend score). While this latter odds ratio (1.08) may appear low, it is quantitatively important as it represents, for an average of 341,098 births/ year in the north of England during 1981-1992, 151 stillbirths/year, which would not have occurred had the risk of stillbirth been the same as in the south of England. After allowing for the north/south zones there remained a significantly higher stillbirth rate in areas with greater deprivation as measured by all three scores during both time periods (see Table 6). Inequality appears to have increased in the more recent time periods (e.g., from an RII for the Townsend score of 1.28 (95\% CI: 1.19-1.37) in 1981-1985 to 1.36 (95\% CI: $1.28-1.45)$ in 1986-1992 with similar changes for the DoE and Jarman scores) and the statistical significance of these changes was tested as before. How- ever, using deprivation scores standardized to the 1981 census for both time periods, these changes in inequality over time were found to be nonsignificant: $(P=0.31,0.37$, and 0.24 for the Townsend, Jarman, and DoE deprivation scores, respectively).

The Hosmer and Lemeshow deciles of risk statistic showed that the Townsend score predicted the number of stillbirths adequately in both time periods $(\mathrm{P}>0.05)$, but the Jarman and DoE scores did so only in the earlier time period ( $\mathrm{P}=0.01$ and 0.02, respectively, for 1986-1992).

\section{Discussion}

\subsection{Strengths and weaknesses of the study}

Over the 44 years of the study the stillbirth rate has declined dramatically, largely as a consequence of improve- 
Table 3

Cumbria: stillbirth rates per 1000 births by time period and social class and quintile of deprivation score

\begin{tabular}{|c|c|c|c|c|c|c|c|c|c|c|c|c|}
\hline & \multicolumn{3}{|l|}{$\underline{1950-65}$} & \multicolumn{3}{|l|}{$\underline{1966-75}$} & \multicolumn{3}{|l|}{$\underline{1976-85}$} & \multicolumn{3}{|l|}{ 1986-93 } \\
\hline & Number & Rate & $95 \% \mathrm{CI}^{\mathrm{a}}$ & Number & Rate & $95 \% \mathrm{CI}^{\mathrm{a}}$ & Number & Rate & $95 \% \mathrm{CI}^{\mathrm{a}}$ & Number & Rate & $95 \% \mathrm{CI}^{\mathrm{a}}$ \\
\hline \multicolumn{13}{|l|}{ Social class } \\
\hline I & 57 & 12.4 & 9.6-16.1 & 29 & 8.8 & $6.1-12.7$ & 18 & 5.0 & $3.1-7.9$ & 12 & 4.2 & $2.4-7.4$ \\
\hline II & 323 & 19.9 & $17.8-22.2$ & 98 & 9.5 & 7.8-11.6 & 76 & 7.6 & $6.0-9.5$ & 44 & 5.3 & $4.0-7.2$ \\
\hline IIIn & 176 & 17.1 & $14.8-19.8$ & 51 & 9.4 & $7.2-12.4$ & 35 & 8.1 & $5.8-11.3$ & 13 & 4.5 & $2.6-7.8$ \\
\hline IIIm & 1073 & 21.8 & $20.6-23.2$ & 400 & 13.8 & $12.5-15.2$ & 152 & 7.2 & $6.1-8.4$ & 72 & 4.4 & $3.5-5.5$ \\
\hline IV & 540 & 24.1 & $22.2-26.3$ & 171 & 16.7 & $14.3-19.3$ & 68 & 8.3 & 6.6-10.6 & 39 & 5.5 & $4.1-7.6$ \\
\hline $\mathrm{V}$ & 306 & 25.5 & $22.8-28.5$ & 78 & 15.2 & 12.1-18.9 & 30 & 6.7 & $4.7-9.7$ & 22 & 5.9 & $3.9-9.0$ \\
\hline Armed forces and unknown & 86 & 21.9 & $17.7-27.1$ & 18 & 15.0 & $9.5-23.9$ & 16 & 25.5 & $15.6-41.6$ & 4 & 3.7 & $1.4-9.9$ \\
\hline Father unrecorded & 171 & 47.8 & $41.1-55.5$ & 80 & 36.1 & $29.0-44.9$ & 33 & 14.1 & $10.0-19.8$ & 29 & 10.3 & $7.1-14.8$ \\
\hline \multicolumn{13}{|l|}{ Deprivation quintile } \\
\hline \multicolumn{13}{|l|}{ Townsend score } \\
\hline 1 (low) & - & - & - & 142 & 10.6 & $9.0-12.5$ & 73 & 6.7 & $5.3-8.4$ & 39 & 4.3 & $3.2-5.9$ \\
\hline 2 & - & - & - & 169 & 12.7 & $10.9-14.7$ & 85 & 7.8 & $6.3-9.6$ & 54 & 6.0 & $4.6-7.8$ \\
\hline 3 & - & - & - & 189 & 14.2 & $12.3-16.3$ & 86 & 7.8 & $6.4-9.7$ & 41 & 4.5 & 3.3-6.2 \\
\hline 5 (high) & - & - & - & 224 & 16.8 & $14.7-19.1$ & 94 & 8.6 & $7.0-10.5$ & 47 & 5.2 & $3.9-6.9$ \\
\hline \multicolumn{13}{|l|}{ DoE Score } \\
\hline 1 (low) & - & - & - & 156 & 11.7 & $10.0-13.7$ & 68 & 6.2 & $4.9-7.9$ & 45 & 5.0 & $3.7-6.7$ \\
\hline 2 & - & - & - & 170 & 12.7 & $11.0-14.8$ & 86 & 7.8 & $6.4-9.7$ & 46 & 5.1 & $3.8-6.8$ \\
\hline 3 & - & - & - & 178 & 13.3 & $11.5-15.4$ & 92 & 8.4 & $6.8-10.3$ & 45 & 5.0 & $3.7-6.7$ \\
\hline 4 & - & - & - & 211 & 15.8 & 13.8-18.1 & 93 & 8.5 & $6.9-10.4$ & 61 & 6.8 & $5.3-8.7$ \\
\hline 5 (high) & - & - & - & 210 & 15.7 & 13.7-18.0 & 89 & 8.1 & $6.6-10.0$ & 38 & 4.2 & $3.1-5.8$ \\
\hline \multicolumn{13}{|l|}{ Jarman Score } \\
\hline 1 (low) & - & - & - & 163 & 12.2 & $10.5-14.2$ & 76 & 6.9 & $5.5-8.7$ & 39 & 4.3 & $3.2-5.9$ \\
\hline 2 & - & - & - & 177 & 13.3 & $11.4-15.4$ & 89 & 8.1 & $6.6-10.0$ & 58 & 6.4 & $5.0-8.3$ \\
\hline 3 & - & - & - & 174 & 13.0 & $11.2-15.1$ & 86 & 7.8 & $6.4-9.7$ & 49 & 5.4 & $4.1-7.2$ \\
\hline 4 & - & - & - & 190 & 14.2 & $12.3-16.4$ & 80 & 7.3 & 5.9-9.1 & 46 & 5.1 & $3.8-6.8$ \\
\hline 5 (high) & - & - & - & 221 & 16.6 & $14.5-18.9$ & 97 & 8.9 & 7.3-10.8 & 43 & 4.8 & $3.5-6.4$ \\
\hline All births & 2732 & 22.4 & 21.6-23.2 & 925 & 13.9 & $13.0-14.8$ & 428 & 7.8 & 7.1-8.6 & 235 & 5.2 & $4.6-5.9$ \\
\hline
\end{tabular}

${ }^{\text {a }}$ Confidence intervals are based on a quadratic approximation to the log likelihood [32].

ments in public health and obstetric and perinatal care [33]. Some of these advances, such as improved antenatal care, which allows more fetuses to be carried to at least 28 weeks, and improved gestational dating, may have increased the number of deaths classified as stillbirths; other advances, such as better fetal monitoring and improved resuscitative abilities, may have decreased the number of stillbirths either by shifting potential stillbirths into the category of neonatal deaths or by preventing infant death. In addition, the introduction of antenatal screening and elective termination has reduced the number of stillbirths due to congenital anomalies in recent years [34,35]. Thus, the clinical characteristics of a stillborn child in the 1950s may be intrinsically different from that of a stillborn child in the 1990s.

Legislation has also affected the number of stillbirths. The 1967 Abortion Act legalized abortion under certain conditions and it has been suggested that this accounted for a substantial fall in the stillbirth rate [36,37]. The gestational age of a fetal death defined as a stillbirth was changed from 28 to 24 weeks in 1992 [16-18]. Thus, a proportion of the 35 stillbirths in Cumbria between 1 October 1992 and 31 December 1993 may have been between 24 and 28 weeks gestation.

However, all analyses were adjusted for year of birth such that the risk of stillbirth for a deprived mother was, in effect, compared with that of other mothers giving birth around the same time. Hence, the objective of the study was not affected by changes in the nature of stillbirths over time.

Underregistration of stillbirths is a possible source of bias. However, exhaustive searches of public archives and hospital records for stillbirths to Cumbrian mothers resulted in only $27(0.6 \%)$ additional stillbirths. In a recent study of births in a different area of England and Wales, national stillbirth registrations proved to be more complete than locally collected stillbirth notifications [38].

\subsection{Summary of results-Cumbria}

In Cumbria, during 1950-1965, when data were available for individual social class but not for community deprivation, there was a highly significant increased risk of stillbirth in less advantaged social classes. In the following time period, 1966-1975, both community deprivation and individual social class were independently associated with stillbirth risk. Inequality in stillbirth risk associated with social class and community deprivation narrowed significantly in more recent years, such that since 1976 there has been no significant association between stillbirth risk and these measures of disadvantage. Births with the father unrecorded were at an exceptionally high risk of stillbirth throughout 


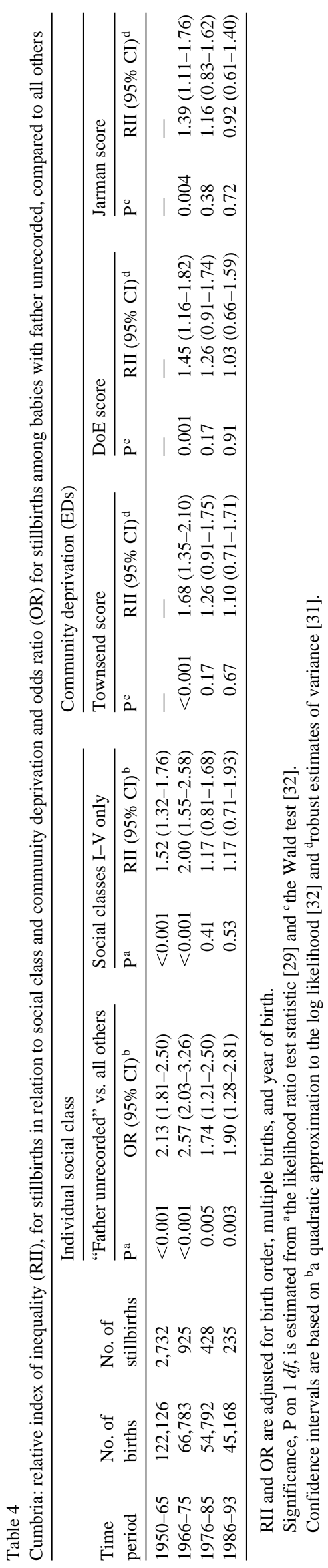

Table 5

England \& Wales: stillbirth rates (95\% CI) per 1000 births by quintile of deprivation score by time period

\begin{tabular}{|c|c|c|c|c|c|c|}
\hline \multirow[b]{2}{*}{ Deprivation quintile } & \multicolumn{3}{|l|}{ 1981-85 } & \multicolumn{3}{|l|}{ 1986-92 } \\
\hline & Number & Rate & $95 \% \mathrm{CI}^{\mathrm{a}}$ & Number & Rate & $95 \% \mathrm{CI}^{\mathrm{a}}$ \\
\hline \multicolumn{7}{|l|}{ Townsend score } \\
\hline 1 (low) & 2274 & 5.1 & $4.9-5.3$ & 2933 & 4.3 & $4.2-4.5$ \\
\hline 2 & 2522 & 5.4 & $5.2-5.7$ & 3156 & 4.3 & $4.2-4.5$ \\
\hline 3 & 2846 & 5.8 & $5.5-6.0$ & 3578 & 4.6 & $4.4-4.7$ \\
\hline 4 & 4118 & 6.1 & $6.0-6.3$ & 4852 & 4.7 & $4.6-4.8$ \\
\hline 5 (high) & 7278 & 6.5 & $6.3-6.6$ & 8695 & 5.4 & $5.3-5.5$ \\
\hline \multicolumn{7}{|l|}{ DoE Score } \\
\hline 1 (low) & 2153 & 5.0 & $4.8-5.2$ & 2917 & 4.4 & $4.2-4.5$ \\
\hline 2 & 2650 & 5.6 & $5.4-5.8$ & 3146 & 4.3 & $4.2-4.5$ \\
\hline 3 & 2802 & 5.9 & $5.6-6.1$ & 3904 & 4.7 & $4.5-4.8$ \\
\hline 4 & 4064 & 6.0 & $5.9-6.2$ & 5083 & 4.8 & $4.7-4.9$ \\
\hline 5 (high) & 7369 & 6.5 & $6.3-6.6$ & 8164 & 5.3 & $5.2-5.4$ \\
\hline \multicolumn{7}{|l|}{ Jarman Score } \\
\hline 1 (low) & 2221 & 5.2 & $5.0-5.4$ & 2836 & 4.3 & $4.2-4.5$ \\
\hline 2 & 2544 & 5.6 & $5.4-5.9$ & 3236 & 4.5 & $4.3-4.6$ \\
\hline 3 & 2915 & 5.6 & $5.4-5.8$ & 3802 & 4.5 & $4.4-4.7$ \\
\hline 4 & 3870 & 6.0 & 5.9-6.2 & 4526 & 4.8 & $4.7-5.0$ \\
\hline 5 (high) & 7488 & 6.4 & $6.3-6.6$ & 8814 & 5.3 & $5.2-5.4$ \\
\hline All births & 19,038 & 6.0 & 5.9-6.0 & 23,214 & 4.8 & $4.7-4.9$ \\
\hline
\end{tabular}

${ }^{\text {a } C o n f i d e n c e ~ i n t e r v a l s ~ a r e ~ b a s e d ~ o n ~ a ~ q u a d r a t i c ~ a p p r o x i m a t i o n ~ t o ~ t h e ~ l o g ~}$ likelihood [32].

the study period, and the proportion of births in this group has more than doubled since the 1950s. This high risk may reflect not only extreme economic disadvantage, but also teenage pregnancies, a lower level of education, and a high prevalence of smoking in this group of women [14,39]. Hence, the overall picture in Cumbria was of narrowing inequality between social strata in the risk of stillbirth from 1966 onwards, with the exception of babies whose fathers were unrecorded.

\subsection{Summary of results-England and Wales}

For England and Wales stillbirth rates were significantly higher in more deprived communities in both 1981-1985 and 1986-1992. There was no evidence of a change in inequality, either increasing or decreasing.

This contrasts with the findings of Sloggett and Joshi [15], who used census-based deprivation indicators and the components of these indicators measured at the individual level in an analysis of stillbirths within the OPCS Longitudinal Study (a 1\% sample of births during 1981-1992 in England and Wales). They found stillbirth risk was not significantly associated with deprivation, social class, or unemployment. Because their study covered the same time period and geographical area as ours, the contrasting findings almost certainly reflect the lower statistical power of their study, which considered 80,835 births in contrast to the $8,039,269$ considered in ours.

\subsection{Comparison of Cumbria with England and Wales}

The continued association between community deprivation and stillbirth risk in England and Wales contrasts with 
Table 6

England and Wales: relative index of inequality for stillbirths in relation to community deprivation for county districts in England and Wales, after adjusting for north/south zone

\begin{tabular}{|c|c|c|c|c|c|c|c|c|}
\hline \multirow[b]{3}{*}{ Time period } & \multirow{3}{*}{$\begin{array}{l}\text { No. of } \\
\text { births }\end{array}$} & \multirow{3}{*}{$\begin{array}{l}\text { No. of } \\
\text { stillbirths }\end{array}$} & \multicolumn{6}{|c|}{ Community deprivation (county districts) } \\
\hline & & & \multicolumn{2}{|c|}{ Townsend } & \multicolumn{2}{|l|}{ DoE } & \multicolumn{2}{|l|}{ Jarman } \\
\hline & & & $\mathrm{p}^{\mathrm{a}}$ & RII $(95 \% \mathrm{CI})^{\mathrm{b}}$ & $\mathrm{p}^{\mathrm{a}}$ & RII $(95 \% \mathrm{CI})^{\mathrm{b}}$ & $\mathrm{p}^{\mathrm{a}}$ & RII $(95 \% \mathrm{CI})^{\mathrm{b}}$ \\
\hline $1981-85$ & $3,199,729$ & 19,038 & $<0.001$ & $1.28(1.19-1.37)$ & $<0.001$ & $1.28(1.19-1.36)$ & $<0.001$ & $1.26(1.18-1.34)$ \\
\hline 1986-92 & $4,839,540$ & 23,214 & $<0.001$ & $1.36(1.28-1.45)$ & $<0.001$ & $1.32(1.24-1.41)$ & $<0.001$ & $1.34(1.26-1.43)$ \\
\hline
\end{tabular}

a Significance, p on 1 d.f., is estimated from the Wald test [32].

${ }^{\mathrm{b}}$ Confidence intervals are based on robust estimates of variance [31].

the situation in Cumbria where there is now no evidence of such an association. This is surprising because, despite the much larger population, the areal units used in England and Wales (county districts) have approximately 300 times the population of those used in Cumbria (enumeration districts) and so almost certainly contain areas of widely different levels of deprivation, thus obscuring the observed association between stillbirth risk and deprivation. While the lack of association between deprivation and stillbirth risk in Cumbria in recent years may be due to the lower number of stillbirths resulting in reduced statistical power, it may also be a consequence of the relative homogeneity of the Cumbrian population, which does not have the extremes of deprivation or affluence present elsewhere in England and Wales (Fig. 3).

Inequality in risk of stillbirth between socioeconomic groups has clearly decreased in Cumbria, whereas no such trend is evident in the rest of England and Wales (Tables 4 and 6). Comparing stillbirth rates in different time periods in Cumbria, it is apparent that the more uniform stillbirth rates in recent years were at least in part a consequence of greater improvement in stillbirth risk in the more disadvantaged communities (Table 3).

It is possible that the differences between England and Wales and Cumbria may be partly due to a higher rate of teenage pregnancy and a lower rate of abortion in the Northern Region, which contains Cumbria [40,41].

\subsection{Changing inequalities in health}

Widening inequalities in health outcome in relation to deprivation have been reported for adult mortality from all and specific causes, and for mortality among children over 5 years old, demonstrating that for these outcomes the overall improvement in the health of our society has been brought about by improvements in the health of its most advantaged members, with proportionately less improvement or even decline among the least advantaged [1,8,42-48]. This contrasts with mortality among infants, where despite a continuing increased risk in less advantaged social classes, inequality between social classes has narrowed over the past 10 years [48]. Our observation of diminishing inequality in stillbirth rate in Cumbria is consistent with that reported for infant mortality and, in contrast with adult mortality, the greatest proportional and absolute falls in stillbirth rates have been in the most deprived. In Cumbria, with the exception of births where the father is unreported, the risk of a pregnancy ending in stillbirth is independent of social status and community deprivation. In contrast, in England and Wales, where the stillbirth rate increased significantly with increasing deprivation, there was no evidence that inequality had diminished. This may reflect the greater diversity in the general population of England and Wales than of Cumbria, where the ethnic minority population is very low ( $0.5 \%$ in the 1991 census compared to a mean of $2.1 \%$ in other counties in England and Wales), where the proportion of unsupported mothers is lower (1.2\% in the 1991 census compared to $1.4 \%$ in other counties in England and Wales), and where the extremes of deprivation are absent (see Fig. 3).

\section{Conclusions}

In England and Wales from 1981 to 1992 and in Cumbria from 1966 to 1975 the risk of stillbirth was greater in more deprived areas, but the inequality in risk with deprivation has not significantly increased nationally and, in Cumbria, has significantly decreased. While historically, both community deprivation and individual social class influenced stillbirths rates independently, rates are becoming low in all groups and the effect of both community and individual disadvantage is becoming very small. The exception remains the children whose father is not reported on the birth certificate, who remain at highest risk.

The diminution of inequality of stillbirth risk between social strata in Cumbria demonstrates that it is possible to remove the lifestyle and environmental component of inequality in health, at least for some outcomes.

However, the stillbirth rate in Cumbria and the remainder of the north of England remains higher than in the south, and the reasons for this remain to be established.

\section{Acknowledgments}

We are grateful to Westlakes Research Institute for funding the project and to the North of England Children's Cancer Research Fund for the ongoing support it gives to the Children's Cancer Research Unit, Newcastle. We thank the 
Office for National Statistics for supplying birth registration data, the late Dr Adam Lawson and Mrs Christine Kinsella for ascertaining stillbirths from hospital records, Mr Julian Smith and Mrs Jane Salotti for continuing maintenance of the Cumbrian birth database, Mrs Katharine Kirton for secretarial assistance and the data entry team in the Department of Child Health, University of Newcastle, for their work in computerising the dataset. This work is based on data provided with the support of the Economic and Social Research Council.

\section{References}

[1] McLoone P, Boddy FA. Deprivation and mortality in Scotland, 1981 and 1991. BMJ 1994;309:1463-70.

[2] Carstairs V, Morris R. Deprivation and mortality: an alternative to social class? Commun Med 1989;11:210-19.

[3] Townsend P, Phillmore P, Beattie A. Health and Deprivation: Inequality and the North. London: Routledge, 1988.

[4] Phillimore P, Beattie A, Townsend P. Widening inequality of health in northern England, 1981-91. BMJ 1994;308:1125-8.

[5] Eames M, Ben-Shlomo Y, Marmot MG. Social deprivation and premature mortality: regional comparison across England. BMJ 1993; 307:1097-102.

[6] Baker D, Taylor H, Henderson J, et al. Inequality in infant morbidity: causes and consequences in England in the 1990s. J Epidemiol Community Health 1998;52:451-8.

[7] Townsend P, Davidson N, editors. Inequalities in Health: the Black Report/Sir Douglas Black. Harmondsworth: Penguin, 1982.

[8] Whitehead M. Inequalities in Health: The Health Divide. London: Penguin, 1988.

[9] Marmot MG, Smith GD, Stansfeld S, et al. Health inequalities among British civil servants: the Whitehall II study. Lancet 1991;337:1387-93.

[10] Pamuk ER. Social-class inequality in infant mortality in England and Wales from 1921 to 1980. Eur J Population 1988;4:1-21.

[11] Parsons L, Duley L, Alberman E. Socioeconomic and ethnic factors in stillbirths and neonatal mortality in the NE Thames Regional Health Authority (NETRHA) 1983. Br J Obstet Gynaecol 1990;97: 237-44.

[12] Woolfe B. Studies of infant mortality-part II. Social aetiology of stillbirths and infant deaths in the county boroughs of England and Wales. J Epidemiol Community Health 1996;50:613-9. (Reprinted and abridged from Br J Soc Prevent Med 1947;2:73-125).

[13] Petridou E, Kotsifakis G, Revinthi K, Polychronopoulou A, Trichopoulos D. Determinants of stillbirth mortality in Greece. Soz Praventivmed 1996;41:70-8.

[14] Arntzen A, Moum T, Magnus P, Bakketeig LS. Marital status as a risk factor for fetal and infant mortality. Scand J Soc Med 1996;24: 36-42.

[15] Sloggett A, Joshi H. Deprivation indicators as predictors of live events 1981-92 based on UK ONS longitudinal study. J Epidemiol Community Health 1998;52:228-33.

[16] Births and Deaths Registration Act 1926. HMSO: London, 1926.

[17] Births and Deaths Registration Act 1953. HMSO: London, 1953.

[18] Stillbirth (Definition) Act 1992. London: HMSO, 1992.

[19] Parker L, Craft AW, Smith J, et al. Geographical distribution of preconceptional radiation doses to fathers employed at the Sellafield nuclear installation, West Cumbria. BMJ 1993;307:966-71.

[20] Parker L, Smith J, Dickinson HO, et al. The creation of a database of workers at a nuclear facility—an exercise in record linkage. Appl Occup Environ Hyg 1997;12:40-5.

[21] Dummer TJB, Dickinson HO, Pearce MS, et al. Stillbirth rates around the nuclear installation at Sellafield, North West England: 1950 1989. Int J Epidemiol 1998;27:74-82.
[22] Golding. The epidemiology of perinatal death. In: Kiely M, editor. Reproductive and Perinatal Epidemiology. Boca Raton: CRC Press, 1990.

[23] Office of Population Censuses and Surveys. Standard Occupational Classification Volumes 1, 2, 3. London: HMSO, 1990.

[24] Department of the Environment. Urban Deprivation. Information note No. 2, Department of the Environment. London: HMSO, 1983.

[25] Jarman B. Identification of underprivileged areas. BMJ 1983;286: 1705-9.

[26] Dolan SA, Jarman B, Bajekal M, Davies PM, Hart D. Measuring disadvantage: changes in the underprivileged area, Townsend, and Carstairs scores 1981-91. J Epidemiol Community Health 1995; 49(suppl. 2):S30-3.

[27] Wagstaff A, Paci P, van Doorslaer E. On the measurement of inequalities in health. Soc Sci Med 1991;33:545-57.

[28] Marang-van de Mheen PJ, Davey Smith G, Hart CL, Gunning-Schepers LJ. Socioeconomic differentials in mortality among men with Great Britain: time trends and contributory causes. J Epidemiol Community Health 1998;52:214-8.

[29] Hosmer DW, Lemeshow S. Applied Logistic Regression. New York: Wiley, 1989.

[30] Efroymson MA. Multiple regression analysis. In: Ralston A, Wilf HS, editors. Mathematical Methods for Digital Computers. New York: Wiley, 1960. pp. 191-203.

[31] Royall RM. Model robust confidence intervals using maximum likelihood estimators. Int Stat Rev 1986;54:221-6.

[32] Clayton D, Hills M. Statistical Models in Epidemiology. Oxford: Oxford University Press, 1993.

[33] Macfarlane A, Chalmers I, Adelstein AM. The role of standardization in the interpretation of perinatal mortality rates. Health Trends 1980; 12:45-50.

[34] Northern Region Health Authority, Regional Fetal Abnormality and Perinatal Mortality Surveys. Collaborative Survey of Perinatal, Late Neonatal and Infant Death in the Northern Region, 1989. Newcastle upon Tyne: Northern Region Health Authority, 1989.

[35] Alberman E, Blatchley N, Botting B, Schuman J, Dunn A. Medical causes on stillbirth certificates in England and Wales: distribution and results of hierarchical classifications tested by the Office for National Statistics. Br J Obstet Gynaecol 1997;104:1043-9.

[36] Abortion Act 1967. HMSO: London, 1967.

[37] Gandy RJ. An estimate of the effect of abortions on the stillbirth rate. J Biosoc. Sci 1979;11:173-8.

[38] Hilder L, Alberman E. Monitoring fetal and infant survival using regional birth notification data in north east London. J Epidemiol Community Health 1998;52:253-8.

[39] Marsh A, McKay S. Poor Smokers. London: Policy Studies Institute, 1996.

[40] Office of Population Censuses and Surveys. Birth Statistics, OPCS Series FM1 Nos. 10-21 Area. London: HMSO, 1983-1991.

[41] Office of Population Censuses and Surveys. Abortion Statistics, OPCS Series AB, Nos. 8-19 Geographic. London: HMSO, 1981-1991.

[42] Davey Smith G, Bartley M, Blane D. The Black report on socioeconomic inequalities in health 10 years on. BMJ 1990;301:373-7.

[43] Wilkinson R. Class mortality differentials, income distribution and trends in poverty 1921-1981. J Social Policy 1989;18:307-35.

[44] Marmot M, McDowall M. Mortality decline and widening social inequalities. Lancet 1986;2:274-6.

[45] Goldblatt P. Mortality by social class, 1971-85. Population Trends 1989;56:6-15.

[46] Blane D, Davey Smith G, Bartley M. Social class differences in years of potential life lost: size, trends, and principal causes. BMJ 1990; 301:429-32.

[47] Shaw M, Dorling D, Brimblecombe N. Changing the map. Sociol Health Illness. 1998;20:694-709.

[48] Botting B. Mortality in childhood. In: Drever D, Whitehead M, editors. Health Inequalities. London: HMSO, 1997. pp. 86-96. 